\title{
In vitro antitumor activity of Latcripin-15 regulator of chromosome condensation 1 domain protein
}

\author{
LI TIAN, XIAOLI WANG, XINGYUN LI, BEN LIU, WEI ZHANG, JING CAO, \\ ANHONG NING, MIN HUANG and MINTAO ZHONG \\ Department of Medical Microbiology, Dalian Medical University, Dalian, Liaoning 116044, P.R. China
}

Received March 8, 2015; Accepted July 22, 2016

DOI: $10.3892 / \mathrm{ol} .2016 .5106$

\begin{abstract}
Cancer is one of the most significant health problems worldwide and thus the development of novel therapeutic agents with fewer side effects is required. The present study investigated the in vitro anticancer effects of a newly isolated fungal protein. In this study, Latcripin-15 (LP-15) regulator of chromosome condensation 1 (RCC1) domain protein, which is obtained from the Lentinula edodes $\mathrm{C}_{91-3}$ fungal strain, was identified, cloned, expressed, purified and re-folded to assess the in vitro antitumor activity of the protein. LP-15 RCC1 full-length cDNA was isolated from Lentinula edodes using 3' and 5'-rapid amplification of cDNA ends and then cloned, expressed, purified and re-folded in vitro. In addition, the effects of the isolated LP-15 RCC1 protein's functional domain on the viability and apoptosis of human lung cancer A549 cells were assessed by 3-(4,5-dimethylthiazol-2-yl)-2,5-diphenyltetrazolium bromide assay, transmission electron microscopy, flow cytometry and Hoechst 33258 staining. The LP-15 RCC1 functional domain protein was successfully expressed, purified and re-folded in vitro. Treatment with the LP-15 RCC1 functional domain protein significantly reduced tumor cell viability and induced apoptosis in A549 cells. The results of the present study indicate that the LP-15 RCC1 functional domain requires further investigation as a novel therapeutic agent for cancer therapy.
\end{abstract}

Correspondence to: Professor Mintao Zhong or Professor Min Huang, Department of Medical Microbiology, Dalian Medical University, 9 Western Section, Lvshun South Road, Dalian, Liaoning 116044, P.R. China

E-mail: dyzhongmt@163.com

E-mail: huangmintea@163.com

Abbreviations: DE3, Rosetta-gami; RACE, rapid amplification of cDNA ends; Clld7, chronic lymphocytic leukemia deletion gene 7; MTT, 3-(4,5-dimethylthiazol-2-yl)-2, 5-diphenyltetrazolium bromide; TEM, transmission electron microscopy; $\mathrm{RCC1}$, regulator of chromosome condensation 1

Key words: Latcripin-15, antitumor activity, apoptosis, Lentinula edodes, prokaryotic expression, $\mathrm{RCC} 1$ domain

\section{Introduction}

Although the early detection, prevention and treatment of cancer has significantly improved in recent decades, it remains the most prevalent and lethal disease, worldwide (1). Based on GLOBOCAN estimates, 14.1 million new cancer cases and 8.2 million cancer-asssociated mortalities occurred in 2012 worldwide (2). Surgery remains the most effective method of curing or controlling the majority of cancers, however, advances in chemotherapy, radiotherapy and specific cancer targeting therapies have significantly improved patient survival, quality of life and prognosis (3). Thus, the development of more potent agents with fewer side effects is key to the effective control of cancer. At present, ongoing studies aim to identify novel and effective methods and novel therapeutics that may be used to combat cancer (1).

Recently, studies investigating medicinal fungi have become an important potential source of novel anticancer drugs $(4,5)$. Lentinula edodes (Shiitake) is a type of edible fungus that has been considered medicinal for hundreds of years (6). Since 1991, increasing evidence has indicated that Lentinula edodes possesses a variety of antitumor, antivirus and immunomodulatory properties (7-9). In vivo and in vitro studies have confirmed that compounds produced by Lentinula edodes induce tumor cell apoptosis. Among these compounds, lentinan is considered to exhibit the most effective suppression of tumor cell proliferation (10-12). Following decades of study, a specialized strain of Lentinula edodes (Lentinula edodes $\mathrm{C}_{91-3}$ ) was generated and fermented protein derived from this strain has been demonstrated to induce apoptosis in numerous tumor cell types, such as A549, S180 and H22 cells (13-15).

In our previous study (16), the functional genomics of Lentinula edodes were investigated by obtaining high-quality DNA sequences ( $>4$ four billion bases) using Illumina/Solexa technology. The data demonstrated the suitability of short-read DNA sequences for de novo assembly and annotation of genes expressed in eukaryotes without prior existing genome information. Our previous study also established a conventional naming system for Lentinula edodes transcriptomic proteins as Lentinula edodes transcriptome protein-(Number) (Latcripin-(Number), LP-(Number) and this nomenclature has been submitted and received by National Center for Biotechnology Information (NCBI) GenBank. In our previous study, 
the Latcripin-1 gene was cloned and expressed in Pichia pastoris and its antitumor properties were analyzed (13). In the present study, Latcripin-15 (LP-15) regulator of chromosome condensation 1 (RCC1) domain protein was identified, cloned, expressed, purified and re-folded from Lentinula edodes $\mathrm{C}_{91-3}$ and the potential of this protein as a novel anti-tumor agent was investigated in vitro.

\section{Materials and methods}

The shiitake strain, Lentinula edodes $\mathrm{C}_{91-3}$, was obtained from The Chinese General Microbiological Culture Collection Center (Beijing, China). Escherichia coli (E . coli) JM109, which was maintained in our laboratory, was used to amplify plasmids for cloning the LP-15 gene. E. coli Rosetta-gami(DE3) cells, used to facilitate expression of LP-15-RCC1 protein, were obtained from Novagen (Merck Millipore, Darmstadt, Germany). The pMD20-T cloning vector was purchased from Takara (Shiga, Japan), while the expression vector pET-32a(+) was purchased from Novagen (Merck Millipore).

The 3'-full rapid amplification of cDNA ends (RACE) core set (Version 2.0), 5'-full RACE kit, miniBEST plasmid purification kit (Version 3.0), miniBEST agarose gel DNA extraction kit (Version 3.0), EcoRI, XhoI, primers, competent cell preparation kit and in-fusion ${ }^{\mathrm{TM}}$ advantage polymerase chain reaction (PCR) cloning kit were also obtained from Takara. TRIzol reagent, mouse anti-His tag monoclonal antibody (catalog no. 66005-1), peroxidase-conjugated affinipure goat anti-mouse immunoglobulin (Ig)G (catalog no. SA00001-1) and nitrocellulose filter membranes were purchased from Invitrogen Life Technologies (Thermo Fisher Scientific, Inc., Waltham, MA, USA). Carbenicillin, chloramphenicol, kanamycin, tetracycline and isopropyl $\beta$-D-thiogalactopyranoside (IPTG) were purchased from Tiangen Biotech Co., Ltd., (Beijing, China). The 6xHis-tagged protein purification kit was purchased from CWBIO (Beijing, China). The bicinchoninic acid (BCA) Protein Assay Kit, Annexin V-fluorescein isothiocyanate (FITC)/propidium iodide (PI) kit and apoptotic cell Hoechst 33258 detection kit were obtained from Keygen Biotech Co., Ltd., (Nanjing, China). The integrated potato culture medium and other common laboratory reagents were prepared in our laboratory.

Cloning of LP-15 RCC1 functional domain cDNA and vector construction. Lentinula edodes $\mathrm{C}_{91-3}$ mycelium was cultured in integrated potato culture medium for 18 days at room temperature. Total RNA was isolated from mycelium culture using TRIzol reagent according to the manufacturer's instructions. Isolated RNA samples were then used as the RACE template. Briefly, primers for 3'-RACE and 5'-RACE experiments were designed using Oligo 6.0 software (Molecular Biology Insights, Inc., Colorado Springs, CO, USA) and Lentinula edodes $\mathrm{C}_{91-3}$ transcriptome sequences, as previously described (16). Experiments were performed using the abovementioned kits, according to the manufacturer's instructions, as previoulsy described (16). The resulting products were DNA sequenced. Full-length cDNA was amplified using PCR and the DNA was sequenced and compared using the NCBI database (http://blast.ncbi.nlm.nih.gov/Blast.cgi). The functional domain sequence of LP-15 was selected and predicted by online tools from Sanger Pfam (http://pfam.xfam.org/). A pair of primers was designed to amplify the functional domain of LP-15 by PCR: Forward, 5'-ATCGGATCCGAATTCCA TGGCAATGTCTACACCTG-3' and reverse, 5'-GTGGTG GTGCTCGAGCAATCCTACGACATGCTGAC-3'. The PCR conditions were as follows: 30 cycles of denaturing at $98^{\circ} \mathrm{C}$ for $10 \mathrm{sec}$, primer annealing at $55^{\circ} \mathrm{C}$ for $10 \mathrm{sec}$, extension at $72^{\circ} \mathrm{C}$ for $1 \mathrm{~min}$ and a final extension at $72^{\circ} \mathrm{C}$ for $5 \mathrm{~min}$. After PCR amplification, a 6xHis-tag was added to the 3 'end of the PCR product for characterization and identification $(17,18)$. EcoRI and $\mathrm{XhoI}$ restriction sites were added to the $\mathrm{N}$ - and C-terminal, respectively, to enable in-fusion ligation (19).

The DNA-sequence-confirmed PCR products were purified using the miniBEST agarose gel DNA extraction kit (Version 3.0) and inserted into pET-32a(+) EcoRI and XhoI sites using the in-fusion ${ }^{\mathrm{TM}}$ advantage PCR cloning kit and E. coli JM109 competent cells. The complete construct was amplified in $E$. coli DE3 cells followed by DNA sequencing. The amino acid composition of the LP-15-RCC1 functional domain was analyzed using the ExPASy database (http://www.expasy.org/). The secondary structure and physicochemical properties of the LP-15-RCC1 functional domain were analyzed using DNAStar software (Version 5.07; DNASTAR Inc., Madison, WI, USA). The tertiary structure of the LP-15-RCC1 functional domain was predicted using the Swiss-Model database (https://swissmodel.expasy.org/interactive).

Expression and purification of the LP-15 RCC1 functional domain protein. pET-32a(+)-LP-15-RCC1 plasmid was transferred into $E$. coli $\mathrm{DE} 3$ cells for protein expression using an in vitro protein expression and purification kit. Briefly, a single bacterial colony was selected and cultured in $10 \mathrm{ml}$ lysogeny broth (LB) medium containing $50 \mu \mathrm{g} / \mathrm{ml}$ carbenicillin, $34 \mu \mathrm{g} / \mathrm{ml}$ chloramphenicol, $15 \mu \mathrm{g} / \mathrm{ml} \mathrm{kanamycin}$ and $12.5 \mu \mathrm{g} / \mathrm{ml}$ tetracycline at $37^{\circ} \mathrm{C}$ in a shaking incubator at $190 \mathrm{rpm}$ overnight. The next day, the culture was transferred to $11 \mathrm{LB}$ medium with the same composition and grown at $37^{\circ} \mathrm{C}$ with shaking at $190 \mathrm{rpm}$ until the optical density (OD), measured at a wavelength of $600 \mathrm{~nm}$, was between 0.5 and 0.6. Next, $1.0 \mathrm{mM}$ IPTG was added to the culture and incubated for an additional $6 \mathrm{~h}$ at $37^{\circ} \mathrm{C}$. pET-32a(+) only was used as a negative control. Finally, the bacterial culture was collected and separated by centrifugation at $6,000 \times \mathrm{g}$ for $20 \min$ at $4^{\circ} \mathrm{C}$.

For protein purification, a portion of the bacterial pellet was subjected to western blot analysis with $12 \%$ sodium dodecyl sulfonate polyacrylate gel electrophoresis (SDS-PAGE) and a primary mouse monoclonal anti-His-antibody at a dilution of 1:250, followed by incubation with secondary peroxidase-conjugated goat anti-mouse $\mathrm{IgG}(\mathrm{H}+\mathrm{L})$ antibody at a dilution of 1:5,000. Western blot analysis confirmed the presence of LP-15-RCC1 protein in the bacteria culture. Next, $100 \mathrm{mg}$ bacteria pellets were lysed using $3 \mathrm{ml}$ bacteria extraction reagent solution $[1 \mathrm{ml}$ bacteria extraction reagent, $1 \mu 1$ DNase I (1,000 U/ml), $2 \mu 1$ Lysozyme $(50 \mathrm{mg} / \mathrm{ml})$ and $10 \mu \mathrm{l}$ phenylmethylsulfonyl fluoride] and incubated at room temperature for $30 \mathrm{~min}$. After incubation, cell lysate was centrifuged at $10,000 \times \mathrm{g}$ for $20 \mathrm{~min}$ at $4^{\circ} \mathrm{C}$ to remove the supernatant. Next, the pellet was resuspended and dissolved in binding buffer (pH 7.9; $8 \mathrm{M}$ urea, $5 \mathrm{mM}$ imidazole, $0.5 \mathrm{M} \mathrm{NaCl}$ and $20 \mathrm{mM}$ 

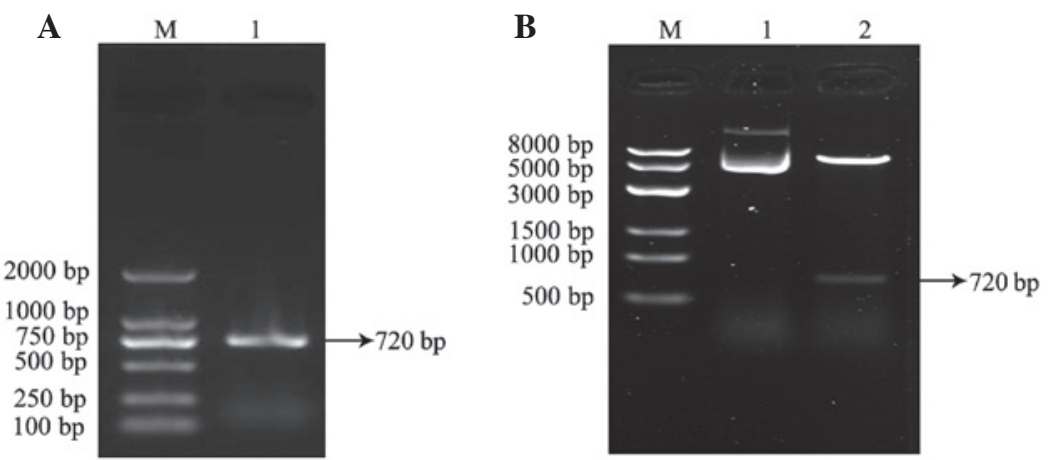

Figure 1. PCR cloning of LP-15 RCC1 functional domain cDNA. (A) 1\% (w/v) agarose gel electrophoresis of LP-15 RCC1 functional domain cDNA. M, DNA Marker DL2000; Lane 1, PCR products of LP-15-RCC1 cDNA. (B) Plasmid pET-32a(+)-LP-15-RCC1 carrying RCC1 functional domain cDNA. M, DNA Marker DL8000; Lane 1, plasmid pET-32a(+)-LP-15-RCC1 extracted from JM109 cells; Lane 2, double restriction enzyme digestion of plasmid pET-32a(+)-LP-15-RCC1 extracted from JM109 cells. RCC1, regulator of chromosome condensation 1; LP-15, Latcripin-15; PCR, polymerase chain reaction.

Tris-HCl; Keygen Biotech Co., Ltd.) at $4^{\circ} \mathrm{C}$ for $1 \mathrm{~h}$. Solubilized protein was then separated from the insoluble cellular debris by centrifugation at $10,000 \times \mathrm{g}$ for $20 \mathrm{~min}$ at $4^{\circ} \mathrm{C}$. The solubilized protein was purified using a nickel-chelated column and washed 15 times with binding buffer prior to elution of the bound protein with elution buffer (pH 7.9; $8 \mathrm{M}$ urea, $500 \mathrm{mM}$ imidazole, $0.5 \mathrm{M} \mathrm{NaCl}$ and $20 \mathrm{mM}$ Tris-HCl). Each eluted fraction was analyzed by $12 \%$ SDS-PAGE to measure the purity of the protein.

Refolding the LP-15 RCC1 functional domain protein. The purified LP-15 RCC1 functional domain protein was refolded by gradient dialysis using four types of the refolding buffer at $4^{\circ} \mathrm{C}$. The four dialysis buffers were: Dialysate 1 [ $4 \mathrm{M}$ urea, $2 \mathrm{mM}$ reduced glutathione $(\mathrm{GSH})$ and $0.2 \mathrm{mM}$ oxidized glutathione (GSSG) in phosphate-buffered saline (PBS)]; Dialysate 2 (2 M urea, $2 \mathrm{mM}$ GSH and $0.2 \mathrm{mM}$ GSSG in PBS); Dialysate 3 (2 mM GSH and $0.2 \mathrm{mM} \mathrm{GSSG}$ in PBS); and Dialysate 4 (PBS). Dialysate was replaced every $8 \mathrm{~h}$ and each concentration of dialysate was used three times. Finally, the refolded protein was concentrated using PEG 12000 (Sigma-Aldrich, Merck Millipore, Darmstadt, Germany) and quantified using the BCA protein assay kit.

Cell culture. The human lung cancer A549 cell line was obtained from the Shanghai Cell Bank, Chinese Academy of Sciences (Shanghai, China) and cultured in RPMI 1640 medium (HyClone Laboratories; GE Healthcare, Logan, UT, USA) supplemented with $10 \%$ fetal bovine serum (FBS; TransGen Biotech, Inc., Beijing, China) in a humidified atmosphere of $5 \% \mathrm{CO}_{2}$ at $37^{\circ} \mathrm{C}$ (to $80 \%$ confluence). To assess the effects of the LP-15 RCC1 functional domain protein on the regulation of cellular behavior and gene expression, A549 cells were seeded in culture plates or flasks at a density of $1 \times 10^{5}$ cells $/ \mathrm{ml}$ and cultured for $24 \mathrm{~h}$. The growth medium was replaced with fresh RPMI 1640 medium with 10\% FBS containing various concentrations $(12.5,25,50,100$ and $200 \mu \mathrm{g}$ ) of the LP-15 RCC1 functional domain protein for the indicated periods of time (24 and $48 \mathrm{~h}$ ) and cellular behavior was subsequently assessed.

3-(4,5-dimethylthiazol-2-yl)-2,5-diphenyltetrazolium bromide (MTT) cell viability assay. The effect of the LP-15 RCC1 functional domain protein on the regulation of cell growth was determined using cell viability MTT assays. Briefly, LP-15 RCC1 functional domain protein with different concentrations $(12.5,25,50,100$ and $200 \mu \mathrm{g})$ was added to cell culture for 24 or $48 \mathrm{~h}$, then $10 \mu \mathrm{l}$ of MTT solution was added to the cell culture medium (Sigma-Aldrich; Merck Millipore) and the cells cultured at $37^{\circ} \mathrm{C}$ in a $5 \% \mathrm{CO}_{2}$ incubator for an additional $4 \mathrm{~h}$. Next, the growth medium was replaced with $150 \mu 1$ dimethyl sulfoxide (Sigma-Aldrich; Merck Millipore). Finally, the absorbance of the cell culture plates was measured at a wavelength of $589 \mathrm{~nm}$ using an ELISA microplate reader (Thermo Fisher Scientific Inc.). Cell viability was determined by the following equation: Cell viability $(\%)=[$ (control group OD - experimental group OD)/control group OD] x 100.

Transmission electron microscopy (TEM). Changes in cellular ultrastructure were assessed following treatment with LP-15 RCC1 functional domain protein using TEM. Following treatment with $200 \mu \mathrm{g}$ LP-15 RCC1 functional domain protein for $48 \mathrm{~h}, \mathrm{~A} 549$ cells were harvested and fixed in $2.5 \%$ glutaraldehyde solution (Sigma-Aldrich; Merck Millipore) at $4^{\circ} \mathrm{C}$ overnight. The next day, the cells were washed with $0.1 \mathrm{M}$ PBS and postfixed with $1 \%(\mathrm{w} / \mathrm{v})$ osmium tetroxide (Sigma-Aldrich; Merck Millipore) for $2 \mathrm{~h}$ at room temperature. After dehydration using a graded ethanol series (70-100\%), cells were embedded in propylene oxide and epon (Sigma-Aldrich; Merck Millipore) and solidified at $60^{\circ} \mathrm{C}$ for $48 \mathrm{~h}$ in $100 \%$ epoxy resin (Sigma-Aldrich, Merck Millipore). Ultrathin sections $(70 \mathrm{~nm})$ were prepared, stained with uranyl acetate and lead citrate (Sigma-Aldrich) Merck Millipore and viewed under a TEM (JEOL Ltd., Tokyo, Japan).

Flow cytometry apoptosis assay. Flow cytometry was performed using FITC-labeled annexin V and PI to detect phosphatidylserine expression as an endpoint indicator of early apoptosis (20). Following 24 or $48 \mathrm{~h}$ treatment with $200 \mu \mathrm{g}$ LP-15 RCC1 functional domain protein, A549 cells were collected and washed in cooled PBS and centrifuged at $111 \mathrm{x} g$ for $5 \mathrm{~min}$ at room temperature. The pellets were then resuspended in $400 \mu \mathrm{l}$ binding buffer and $5 \mu \mathrm{l}$ FITC-labeled annexin $\mathrm{V}$ and $5 \mu \mathrm{l} \mathrm{PI}$ were added to the suspension. The cells were gently mixed, then incubated at the room temperature in the dark for $15 \mathrm{~min}$. Fluorescence intensity was detected 
A

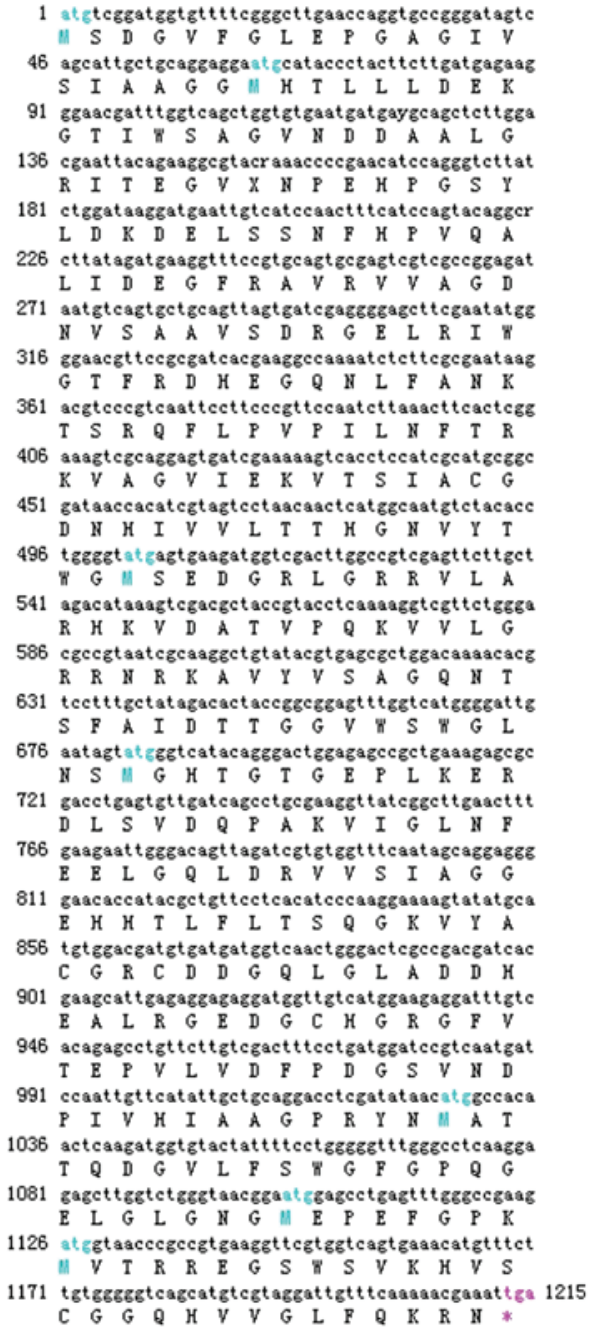

B

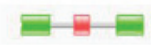

$\mathrm{RCCl} \mathrm{RCCl}_{2} 2 \mathrm{RCC}$

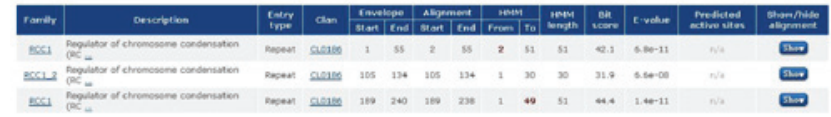

Figure 2. LP-15 protein amino acid sequencing. (A) Amino acid sequence of the full-length LP-15 coding sequence region. (B) Functional domain analysis of the LP-15-RCC1 protein using the Pfam database. RCC1, regulator of chromosome condensation 1; LP-15, Latcripin-15.

using a flow cytometer and analyzed using Cell Quest software (Version 3.3; Cell Quest, Inc., Tokyo, Japan).

Hoechst 33258 staining. Cells were cultured on coverslips and treated with $50 \mu \mathrm{g}$ or $100 \mu \mathrm{g}$ LP-15 RCC1 functional domain protein for $48 \mathrm{~h}$. Cells were then stained with $5 \mu \mathrm{g}$ Hoechst 33258 (Keygen Biotech Co., Ltd.) in PBS at room temperature in the dark for $10 \mathrm{~min}$. After staining, the cells were washed twice with PBS and images were captured using a fluorescence microscope (Nikon Corporation, Tokyo, Japan) with an excitation waveleng th of 330-380 $\mathrm{nm}$.

Statistical analysis. All experiments were performed in duplicate and repeated at least three times. Data are expressed as the mean \pm standard deviation. Treatment groups were compared using one-way analysis of variance with SPSS 13.0
C

Amino acid composition:

$\begin{array}{lrr}\text { Ala (A) } & 13 & 5.4 \% \\ \text { Arg (R) } & 15 & 6.2 \% \\ \text { Asn (N) } & 8 & 3.3 \% \\ \text { Asp (D) } & 15 & 6.2 \% \\ \text { Cys (C) } & 4 & 1.7 \% \\ \text { Gln (Q) } & 9 & 3.8 \% \\ \text { Glu (E) } & 13 & 5.4 \% \\ \text { Gly (G) } & 37 & 15.4 \% \\ \text { His (H) } & 10 & 4.2 \% \\ \text { Ile (I) } & 5 & 2.1 \% \\ \text { Leu (L) } & 19 & 7.9 \% \\ \text { Lys (K) } & 8 & 3.3 \% \\ \text { Met (M) } & 5 & 2.1 \% \\ \text { Phe (F) } & 8 & 3.3 \% \\ \text { Pro (P) } & 10 & 4.2 \% \\ \text { Ser (S) } & 13 & 5.4 \% \\ \text { Thr (T) } & 13 & 5.4 \% \\ \text { Trp (W) } & 5 & 2.1 \% \\ \text { Tyr (Y) } & 4 & 1.7 \% \\ \text { Val (V) } & 26 & 10.8 \% \\ \text { Pyl (O) } & 0 & 0.0 \% \\ \text { Sec (U) } & 0 & 0.0 \%\end{array}$

(B) $0 \quad 0.0 \%$

(Z) $0 \quad 0.0 \%$

(X) $0.0 \%$

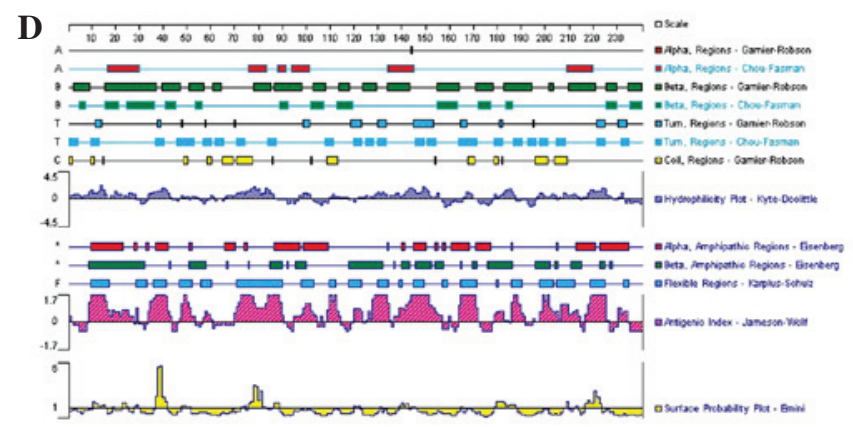

$\mathbf{E}$

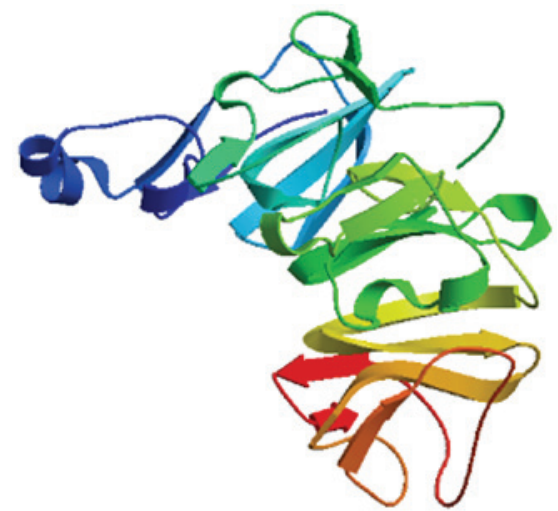

Figure 2. Continued. (C) Amino acid composition of the LP-15-RCC1 functional domain protein. (D) Secondary and (E) tertiary structures of the LP-15-RCC1 functional domain protein. LP-15, Latcripin-15.

(SPSS, Inc., Chicago, IL, USA). P $<0.05$ was considered to indicate a statistically significant difference.

\section{Results}

Cloning, expression and purification of LP-15 RCCl functional domain protein. LP-15 RCC1 functional domain cDNA 
A

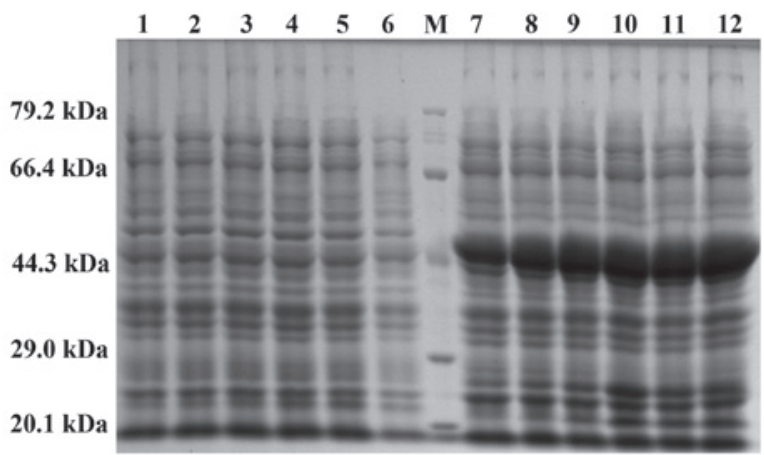

B 1 $\begin{array}{llllll}2 & 3 & 4 & 5 & 6 & 7\end{array}$
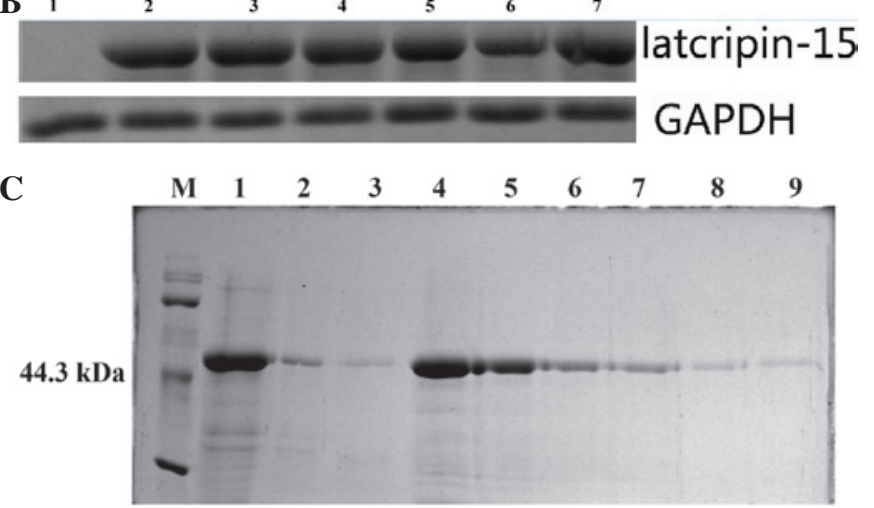

Figure 3. Expression, purification and identification of the LP-15 RCC1 functional domain protein. (A) $12 \%$ SDS-PAGE of the cell lysate. Lanes 1-6, total cell lysate from DE3 induced using $1 \mathrm{mM}$ IPTG for 6, 5, 4, 3, 2 and $1 \mathrm{~h}$, respectively. pET-32a $(+)$ served as a negative control. $\mathrm{M}$, molecular weight marker. Lanes 7-12, total cell lysate from DE3 with pET-32a(+)-LP-15-RCC1 induced using $1 \mathrm{mM}$ IPTG for 1, 2, 3, 4, 5 and $6 \mathrm{~h}$, respectively. (B) Western blot of pET-32a(+)-LP-15-RCC1. Lane 1, total cell lysate from DE3 induced with $1 \mathrm{mM}$ IPTG for $6 \mathrm{~h}$. pET-32a(+) served as a negative control. Lanes 2-7, total cell lysate from DE3 cells with pET-32a(+)-LP-15-RCC1 induced using $1 \mathrm{mM}$ IPTG for 1, 2, 3, 4, 5 and $6 \mathrm{~h}$, respectively. (C) 12\% SDS-PAGE of purified protein. M, protein molecular weight marker. Lane 1, total cell lysate after solubilization with buffer containing $8 \mathrm{M}$ urea. Lane 2, liquid flow through from the $\mathrm{Ni}^{2+}$ column following addition of pET-32a(+)-LP-15-RCC1 sample. Lane 3, first phase eluent. Lane 4, second phase eluent. Lane 5 , third phase eluent. Lane 6, fourth phase eluent. Lane 7, fifth phase eluent. Lane 8, sixth phase eluent. Lane 9, seventh phase eluent. RCC1, regulator of chromosome condensation 1; LP-15, Latcripin-15; IPTG, isopropyl $\beta$-D-thiogalactopyranoside; SDS-PAGE, sodium dodecyl sulfonate polyacrylate gel electrophoresis; GAPDH, glyceraldehyde 3-phosphate dehydrogenase; DE3, Rosetta-gami.

was cloned from Lentinula edodes $\mathrm{C}_{91-3}$ using 3'-RACE and 5'-RACE (Fig. 1A). DNA sequencing confirmed that the correct 720 base pair (bp) fragment had been cloned (Fig. 1B). The amino acid sequence of the LP-15 full-length cDNA coding sequence region has been submitted to GenBank (Accession Number, KF709447; Fig. 2A). The amino acid sequence of the LP-15 functional domain was analyzed using the Pfam database (http://pfam.xfam.org/). The result shown in the Pfam-A database matched the RCC1 domains: A 720 bp-long open reading frame encoding 240 amino acids (Fig. 2B). The amino acid composition of the LP-15 functional domain was analyzed using the ExPASy database (http://www.expasy.org/) (Fig. 2C). The secondary structure of the LP-15 functional domain indicated that it contained ordinary $\alpha, \beta$, turn and coil regions (Fig. 2D). The tertiary structure of the LP-15-RCC1 functional domain is shown in Fig. 2E with a predicted molecular weight (MW) of

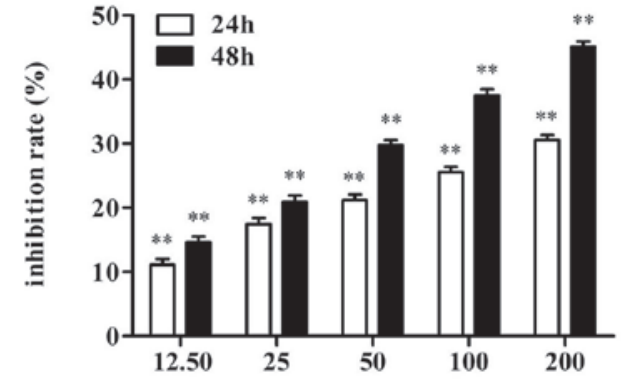

LP-15 RCC1 domain protein concentration $(\mu \mathrm{g} / \mathrm{ml})$

Figure 4. Effect of 24 and $48 \mathrm{~h}$ treatment with 12.5, 25, 50, 100 and $200 \mu \mathrm{g}$ LP-15 RCC1 functional domain protein on A549 cell viability. Tumor cell viability was significantly reduced in a time- and dose-dependent manner. ${ }^{* *} \mathrm{P}<0.01$ vs. control.
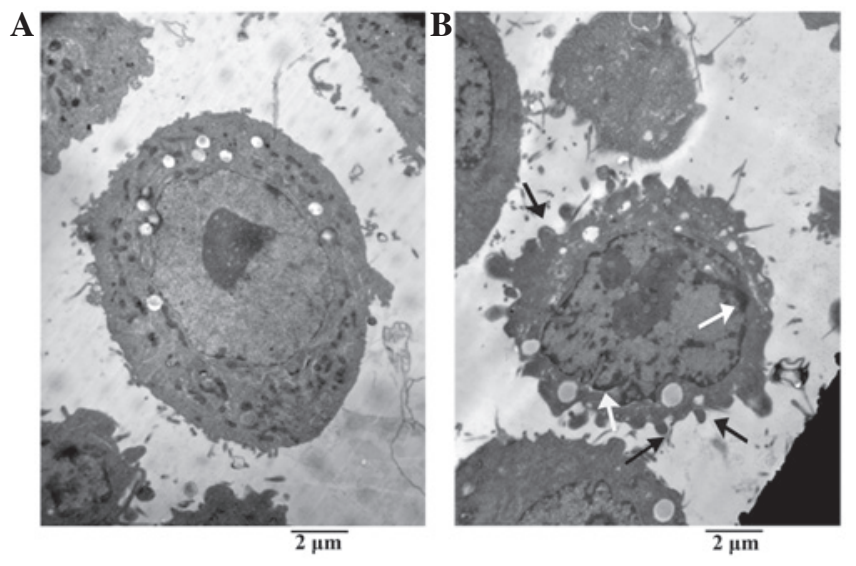

Figure 5. Effect of LP-15 RCC1 functional domain protein treatment on tumor cell morphology. (A) Control A549 cells exhibited regular morphology, with large nuclei and numerous mitochondria. (B) A549 cells treated with $200 \mu \mathrm{g}$ Latcripin-15 RCC1 functional domain protein for $48 \mathrm{~h}$ exhibited apoptotic bodies (black arrow), chromatin condensation (white arrow), nuclear fragmentation and decreased numbers of mitochondria (magnification, x1,000). RCC1, regulator of chromosome condensation; LP-15, Latcripin-15.

$25.80 \mathrm{kDa}$ and isoelectric point (pI) of 6.33. The predicted MW and $\mathrm{pI}$ of the $\mathrm{pET}-32 \mathrm{a}(+)-\mathrm{LP}-15-\mathrm{RCC} 1$ recombinant protein were $44.85 \mathrm{kDa}$ and 6.09 , respectively. After completing this analysis, the LP-15 RCC1 functional domain protein, which appeared at approximately $45 \mathrm{kDa}$ on a $12 \%$ SDS-PAGE gel, was expressed, purified and refolded in vitro (Fig. 3).

LP-15 RCC1 functional domain protein reduces A549 cell viability. The effect of the LP-15 RCC1 functional domain protein on the regulation of A549 cell viability was assessed. Following tumor cell incubation with various concentrations of LP-15 RCC1 functional domain protein for $24 \mathrm{~h}$ or $48 \mathrm{~h}$, tumor cell viability was significantly reduced in a time- and dose-dependent manner ( $\mathrm{P}<0.001 ;$ Fig. 4). In comparison to the controls, cell viability inhibition rates were $29.75 \pm 5.8$, $37.50 \pm 4.2$ and $45.16 \pm 1.85$ after $48 \mathrm{~h}$ treatment with 50, 100 and $200 \mu \mathrm{g}$ RCC1 functional domain protein, respectively.

Treatment with LP-15 RCC1 functional domain protein induces morphological changes in A549 cells. The morphological changes in A549 cells following treatment with $200 \mu \mathrm{g}$ LP-15 

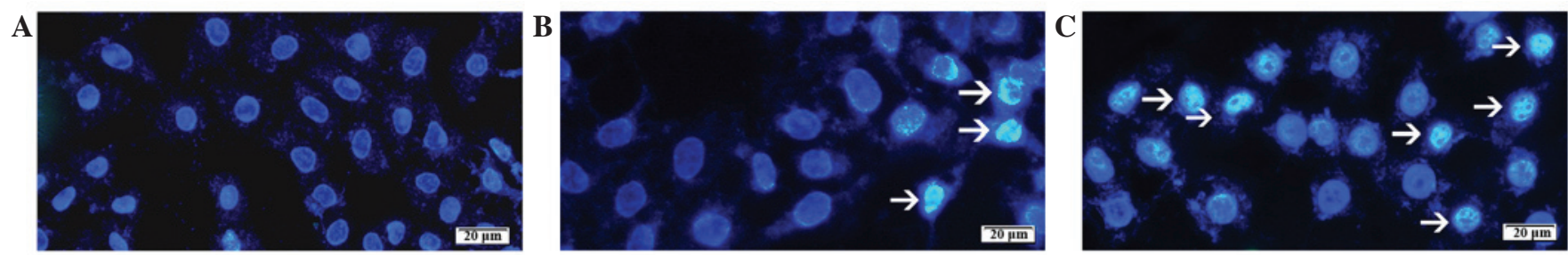

Figure 6. Hoechst 33258 staining of A549 cells treated with 50 or $100 \mu \mathrm{g}$ Latcripin-15 RCC1 functional domain protein for $48 \mathrm{~h}$. (A) Control A549 cells. A549 cells treated with (B) $50 \mu \mathrm{g}$ and $100 \mu \mathrm{g}$ Latcripin-15 RCC1 functional domain protein exhibited apoptosis (arrows indicate apoptotic cells. RCC1, regulator of chromosome condensation 1 .
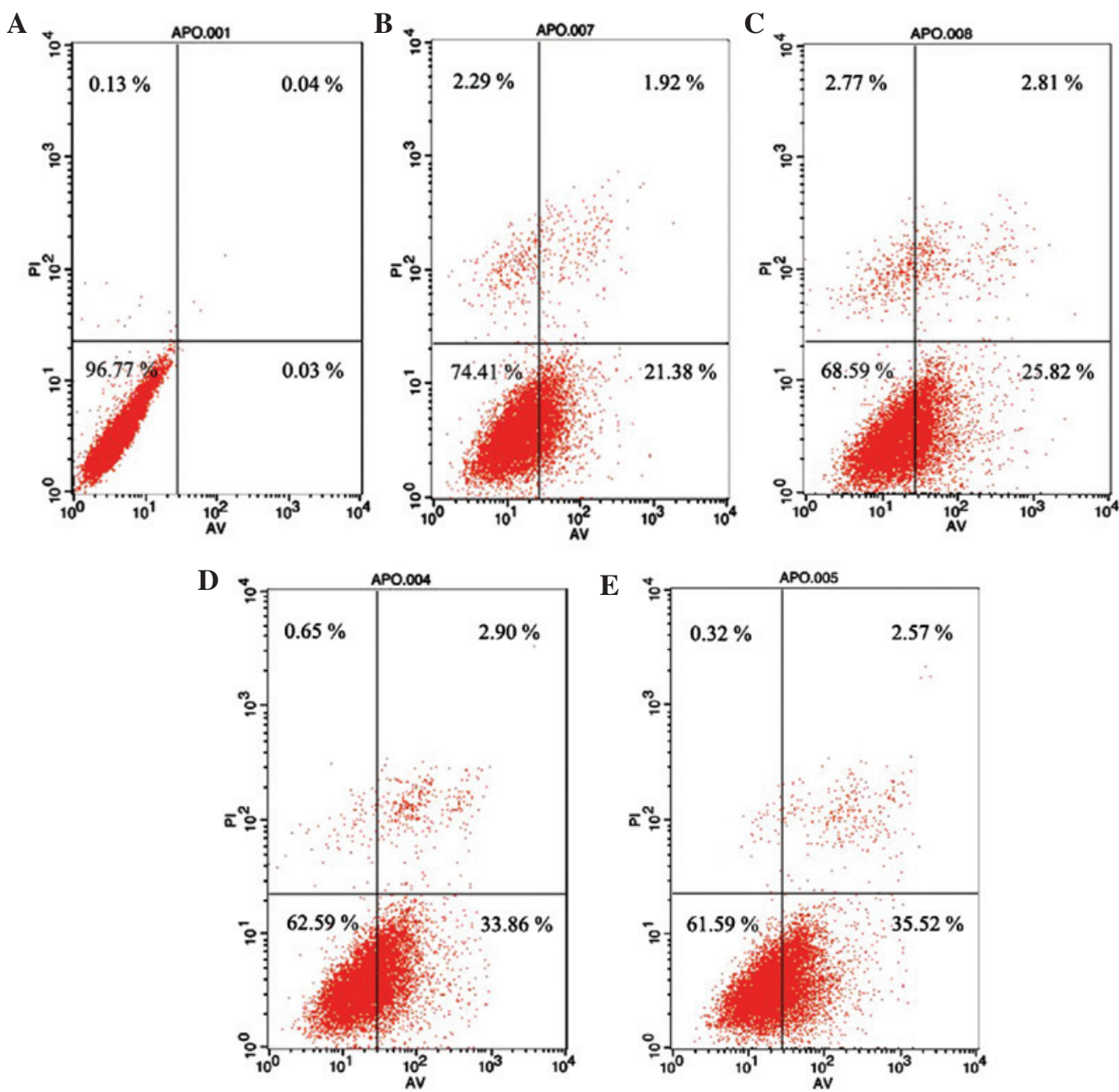

Figure 7. Flow cytometry of A549 cells following treatment with Latcripin-15 RCC1 functional domain protein. (A) Control cells. Treatment with (B) $100 \mu \mathrm{g}$ and (C) $200 \mu \mathrm{g}$ Latcripin-15 RCC1 functional domain protein for $24 \mathrm{~h}$ promoted tumor apoptosis. Treatment with (D) $100 \mu \mathrm{g}$ and (E) $200 \mu \mathrm{g}$ Latcripin-15 $\mathrm{RCC} 1$ functional domain protein for $48 \mathrm{~h}$ promoted tumor apoptosis. Tumor cell apoptosis was increased in a dose-dependent manner. RCC1, regulator of chromosome condensation 1 .

RCC1 functional domain protein for $48 \mathrm{~h}$ was assessed using TEM (Fig. 5). A549 cells in the control group maintained regular morphology, with a large nucleus, numerous mitochondria and membrane phase structural integrity (Fig. 5A). By contrast, after LP-15 RCC1 functional domain treatment, tumor cells exhibited apoptotic bodies, chromatin condensation, nuclear fragmentation and decreased numbers of mitochondria (Fig. 5B).

Treatment with LP-15 RCC1 functional domain protein induces apoptotic changes in A549 cells. Apoptotic A549 cells were identified using Hoechst 33258 staining following treatment with 50 and $100 \mu \mathrm{g}$ LP-15 RCC1 functional domain protein for $48 \mathrm{~h}$. Analysis of nuclear morphology identified cellular changes associated with apoptosis, such as chromatin condensation and fragmentation. Following $48 \mathrm{~h}$ treatment with 50 and $100 \mu \mathrm{g}$ LP-15 RCC1 functional domain protein, fluorescence microscopy revealed apoptotic tumor cells exhibiting chromatin condensation (Fig. 6).

A459 cells were also analyzed using Annexin V/PI-flow cytometry following treatment with 100 and $200 \mu \mathrm{g} \mathrm{LP}-15$ $\mathrm{RCC} 1$ functional domain protein for 24 and $48 \mathrm{~h}$. After $24 \mathrm{~h}$ treatment with 100 and $200 \mu \mathrm{g}$ LP-15 RCC1 functional 
domain protein, the early and advanced apoptosis rates of A549 cells were 1.92 and $21.38 \%$ and 2.81 and $25.82 \%$, respectively. After $48 \mathrm{~h}$ treatment with 100 and $200 \mu \mathrm{g} \mathrm{LP}-15$ RCC1 functional domain protein, the early and advanced apoptosis rates were 2.90 and $33.86 \%$ and 2.57 and $35.52 \%$, respectively. These results indicate that treatment with LP-15 $\mathrm{RCC} 1$ functional domain protein increases the apoptosis rate of A549 cells in a dose-dependent manner (Fig. 7).

\section{Discussion}

The identification of novel anticancer drugs has progressed from a strategy that primarily focused on agents that kill tumor cells to a more mechanistic strategy focused on understanding the molecular targets involved in tumor signaling and tumor cell transformation (21). In the present study, a novel LP-15 RCC1 functional domain protein, obtained from Lentinula edodes $\mathrm{C}_{91-3}$, was identified, cloned, expressed, purified and refolded to assess the antitumor activity of the protein in vitro. The treatment of A549 cells with the LP-15 RCC1 functional domain protein significantly reduced tumor cell viability and induced tumor cells to undergo apoptosis. Thus, this protein presents a potential novel anticancer therapeutic agent, however, further in vivo studies are required.

The RCC1 domain of the LP-15 protein may be critical to its antitumor properties. RCC1 is a RAs-related nuclear protein (Ran) guanine nucleotide exchange factor for Ran guanosine triphosphate (GTP)ase, which exhibits a critical function in mitosis, nucleocytoplasmic transport and nuclear envelope assembly (22). RCC1 catalyzes the exchange of RanGDP to RanGTP, which is essential for nucleocytoplasmic transport (23) and spindle and nuclear envelope assembly during mitosis (24,25). Cáceres-Gorriti et al (26) demonstrated that the RAN network, including RAN's nucleocytoplasmic transport and mitotic functions, is dysregulated in serous ovarian carcinomas and this dysregulation affects tumor progression and patient survival. Wong et al (27) reported that nuclear RanGTP levels exhibit a crucial function in apoptosis initiation and RCC1 reads the histone code generated by caspase-activated Mst1 to initiate apoptosis by reducing RanGTP levels in the nucleus. Additionally, Zhou and Münger (28) reported that the chronic lymphocytic leukemia deletion gene 7 (Clld7) gene, which encodes an evolutionarily conserved protein carrying an RCC1 domain in addition to broad complex, tramtrack, bric-a-brac and POxvirus and Zinc finger domains, reduces cell viability. $C l l d 7$ depletion in normal human epithelial cells confers resistance to DNA damage-induced apoptosis (28). The present current study provides further evidence to support the hypothesis that the RCC1 domain protein possesses pro-apoptotic or programmed cell death activity.

Latcripin-1, a similar apoptosis-related protein isolated from the Lentinula edodes $\mathrm{C}_{91-3}$ transcriptome, has been expressed using a eukaryotic expression system (13). In our previous study, the Latcripin-13 RCC1 and plant homeodomain proteins were successfully expressed in a prokaryotic expression system (E. coli DE3) (14). As a result of our previous study, and due to the extensive amount of time and effort required to generate sufficient protein concentrations using the eukaryotic expression system, a prokaryotic expression system was selected for the present study. The advantages of the prokaryotic expression system include speed, high capacity, ease of operation and low cost (29-31). To date, few studies investigating the antitumor activity of $\mathrm{RCC} 1$ domain proteins have been reported in the literature. Thus, although the antitumor mechanism of RCC1 remains to be determined, the results of the present study represent a novel and significant step towards understanding the antitumor activity of this protein domain. However, the current study has a number of limitations, which must be considered. While the present study successfully demonstrated the antitumor activity of the LP-15 RCC1 domain protein in vitro, future studies are required to focus on understanding its molecular antitumor mechanisms. Additionally, in the future we aim to develop an in vivo expression system to express this protein directly in tumor cells and assess its antitumor activity and underlying mechanisms in vivo.

\section{Acknowledgements}

This study was supported in part by The National Natural Science Foundation of China (grant no. 81301995).

\section{References}

1. Wang J, Zhao B, Zhang W, Wu X, Wang R, Huang Y, Chen D, Park K, Weimer BC and Shen Y: Mycoepoxydiene, a fungal polyketide, induces cell cycle arrest at the G2/M phase and apoptosis in HeLa cells. Bioorg Med Chem Lett 20: 7054-7058, 2010.

2. Torre LA, Bray F, Siegel RL, Ferlay J, Lortet-Tieulent J and Jemal A: Global cancer statistics, 2012. CA Cancer J Clin 65: 87-108, 2015.

3. Bernier J and Cooper JS: Chemoradiation after surgery for high-risk head and neck cancer patients: How strong is the evidence? Oncologist 10: 215-224, 2005.

4. Sharvit LE, Wasser SP and Fares F: The effect of culture liquid ethyl acetate mycelium extracts of medicinal mushrooms on the viability of human pancreatic cancer cells. Int J Med Mushrooms 14: 169-179, 2012.

5. Petrova RD: New scientific approaches to cancer treatment: Can medicinal mushrooms defeat the curse of the century? Int J Med Mushrooms 14: 1-20, 2012.

6. Jeff IB, Li S, Peng X, Kassim RM, Liu B and Zhou Y: Purification, structural elucidation and antitumor activity of a novel mannogalactoglucan from the fruiting bodies of Lentinus edodes. Fitoterapia 84: 338-346, 2013.

7. Finimundy TC, Gambato G, Fontana R, Camassola M, Salvador M, Moura S, Hess J, Henriques JA, Dillon AJ and Roesch-Ely M: Aqueous extracts of Lentinula edodes and Pleurotus sajor-caju exhibit high antioxidant capability and promising in vitro antitumor activity. Nutr Res 33: 76-84, 2013.

8. Hearst R, Nelson D, McCollum G, Millar BC, Maeda Y, Goldsmith CE, Rooney PJ, Loughrey A, Rao JR and Moore JE: An examination of antibacterial and antifungal properties of constituents of Shiitake (Lentinula edodes) and Oyster (Pleurotus ostreatus) mushrooms. Complement Ther Clin Pract 15: 5-7, 2009.

9. Liu Y, Yuan Y, Lei XY, Yang H, Ibrahim SA and Huang W: Purification and characterisation of two enzymes related to endogenous formaldehyde in Lentinula edodes. Food Chem 138: 2174-2179, 2013.

10. Jeff IB, Yuan X, Sun L, Kassim RM, Foday AD and Zhou Y: Purification and in vitro anti-proliferative effect of novel neutral polysaccharides from Lentinus edodes. Int J Biol Macromol 52: 99-106, 2013.

11. Suzuki N, Takimoto Y, Suzuki R, Arai T, Uebaba K, Nakai M, Strong JM and Tokuda H: Efficacy of oral administration of Lentinula eododes mycelia extract for breast cancer patients undergoing postoperative hormone therapy. Asian Pac J Cancer Prev 14: 3469-3472, 2013.

12. Tanaka K, Matsui Y, Ishikawa S, Kawanishi T and Harada M: Oral ingestion of Lentinula edodes mycelia extract can restore the antitumor $\mathrm{T}$ cell response of mice inoculated with colon-26 cells into the subserosal space of the cecum. Oncol Rep 27: 325-332, 2012 . 
13. Liu B, Zhong M, Lun Y, Wang X, Sun W, Li X, Ning A, Cao J, Zhang W, Liu L and Huang M: A novel apoptosis correlated molecule: Expression and characterization of protein Latcripin-1 from Lentinula edodes C(91-3). Int J Mol Sci 13: 6246-6265, 2012.

14. Wang J, Zhong M, Liu B, Sha L, Lun Y, Zhang W, Li X, Wang X, Cao J, Ning A and Huang M: Expression and functional analysis of novel molecule-Latcripin-13 domain from Lentinula edodes C91-3 produced in prokaryotic expression system. Gene 555: 469-475, 2015.

15. Li X, Zhong M, Liu B, Wang X, Liu L, Zhang W and Huang M: Antiproliferative protein from the culture supernatant of Lentinula edodes C91-3 mycelia. J Agric Food Chem 62: 5316-5320, 2014.

16. Zhong M, Liu B, Wang X, Liu L, Lun Y, Li X, Ning A, Cao J and Huang M: De novo characterization of Lentinula edodes C91-3 transcriptome by deep Solexa sequencing. Biochem Biophys Res Commun 431: 111-115, 2013.

17. Bu D, Zhou Y, Tang J, Jing F and Zhang W: Expression and purification of a novel therapeutic single-chain variable fragment antibody against BNP from inclusion bodies of Escherichia coli. Protein Expr Purif 92: 203-207, 2013.

18. Guo L, Liu K, Zhao W, Li X, Li T, Tang F, Zhang R, Wu W and $\mathrm{Xi}$ T: Immunological features and efficacy of the reconstructed epitope vaccine CtUBE against Helicobacter pyloriinfection in BALB/c mice model. Appl Microbiol Biotechnol 97: 2367-2378, 2013.

19. Ganguly A, Malabadi RB, Das D, Suresh MR and Sunwoo HH: Enhanced prokaryotic expression of dengue virus envelope protein. J Pharm Pharm Sci 16: 609-621, 2013.

20. Vermes I, Haanen C, Steffens-Nakken H and Reutelingsperger C: A novel assay for apoptosis. Flow cytometric detection of phosphatidylserine expression on early apoptotic cells using fluorescein labelled Annexine V. J Immunol Methods 184: 39-51, 1995.

21. Dai QS, Liu W, Wang XB, Lu N, Gong DD, Kong LY and Guo QL: NCPMF-60 induces G2/M cell cycle arrest and apoptosis in human hepatocellular carcinoma HepG2 cells. Anticancer Drugs 22: 46-57, 2011.
22. Chen T, Muratore TL, Schaner-Tooley CE, Shabanowitz J, Hunt DF and Macara IG: N-terminal alpha-methylation of RCC1 is necessary for stable chromatin association and normal mitosis. Nat Cell Biol 9: 596-603, 2007.

23. Izaurralde E, Kutay U, von Kobbe C, Mattaj IW and Görlich D: The asymmetric distribution of the constituents of the Ran system is essential for transport into and out of the nucleus. EMBO J 16: 6535-6547, 1997.

24. Hetzer M, Gruss OJ and Mattaj IW: The Ran GTPase as a marker of chromosome position in spindle formation and nuclear envelope assembly. Nat Cell Biol 4: E177-E184, 2002.

25. Quimby BB and Dasso M: The small GTPase Ran: Interpreting the signs. Curr Opin Cell Biol 15: 338-344, 2003.

26. Cáceres-Gorrit KY, Carmona E, Barrès V, Rahimi K, Létourneau IJ, Tonin PN, Provencher D and Mes-Masson AM: Ran nucleo-cytoplasmic transport and mitotic spindle assembly partners XPO7 and TPX2 are new prognostic biomarkers in serous epithelial ovarian cancer. PLoS One 9: e91000, 2014.

27. Wong CH, Chan H, Ho CY, Lai SK, Chan KS, Koh CG and Li HY: Apoptotic histone modification inhibits nuclear transport by regulating RCC1. Nat Cell Biol 11: 36-45, 2009.

28. Zhou X and Münger K: Clld7, a candidate tumor suppressor on chromosome 13q14, regulates pathways of DNA damage/repair and apoptosis. Cancer Res 70: 9434-9443, 2010.

29. Bachran C, Abdelazim S, Fattah RJ, Liu S and Leppla SH: Recombinant expression and purification of a tumor-targeted toxin in Bacillus anthracis. Biochem Biophys Res Commun 430: 150-155, 2013.

30. Jeong TH, Son YJ, Ryu HB, Koo BK, Jeong SM, Hoang P, Do BH, Song JA, Chong SH, Robinson RC and Choe $\mathrm{H}$ : Soluble expression and partial purification of recombinant human erythropoietin from E. coli. Protein Expr Purif 95: 211-218, 2014

31. Li R, Dan X and Li A: Siganus oramin recombinant L-amino acid oxidase is lethal to Cryptocaryon irritans. Fish Shellfish Immunol 35: 1867-1873, 2013. 